\title{
Mortality in a cohort of tannery workers
}

\author{
Fabio Montanaro, Marcello Ceppi, Paul A Demers, Riccardo Puntoni, Stefano Bonassi
}

\begin{abstract}
Objectives-To evaluate the mortality of a group of tannery workers.

Methods-The cohort consisted of 1244 workers (870 men and 374 women) employed at a chrome tannery between 1955 and 1988. A total of 36414 person-years of follow up was calculated (369 people had died). National and regional mortalities were used to estimate the expected numbers.

Results-All cause mortality was similar to that of the general population. The most remarkable excess was for bladder cancer (observed 10, standardised mortality ratio (SMR) 242, 95\% confidence interval (95\% CI) 116 to 446). An excess of colorectal cancer (observed 17, SMR 180, 95\% CI 105 to 288) was also found, based on an increased risk of both colon (SMR 166) and rectal cancer (SMR 206). No recognisable patterns emerged from the analyses by years since first employment, calendar year of hire, or lagging exposures.

Conclusions-The increased mortality from bladder cancer is likely due to exposure to benzidine based leather dyes. If the apparent excess of colorectal cancer is real, its causes are as yet unknown.
\end{abstract}

(Occup Environ Med 1997;54:588-591)

Keywords: leather workers; tannery workers; bladder cancer

Department of Environmental Epidemiology, Istituto Nazionale per la Ricerca sul Cancro, Genoa, Italy F Montanaro M Ceppi

R Puntoni

$S$ Bonassi

Occupational Hygiene Programme,

University of British

Columbia, Vancouver, Canada

P A Demers

Correspondence to: Dr Stefano Bonassi, Department of Environmental Epidemiology, Istituto Nazionale per la Ricerca sul Cancro, Largo Rosanna Benzi 10, 16132-Genova, Italy.

Accepted 26 February 1997
Work in tanneries may involve potential exposure to several known or suspected human carcinogens. Chromium salts, benzidine based azo dyes, formaldehyde, aromatic organic solvents, nitrosamines, and leather dust are the most often reported agents, although the presence of other potentially harmful chemicals in the various steps of the tanning process has been well documented. ${ }^{12}$ The risk of cancer associated with employment in the leather tanning industry was reviewed by the International Agency for Research on Cancer in 1981 and again in 1987, and on both occasions the evidence was considered insufficient. ${ }^{13}$

Since 1987, further studies of tannery workers ${ }^{5-8}$ have been published. Cohort studies of tannery workers ${ }^{4-12}$ and workers who perform similar operations in the fur industry ${ }^{5}{ }^{13}$ have been conducted in Europe, North America, and China and other information has become available from community based case-control studies. Excesses of lung, ${ }^{6} 7101113$ bladder, ${ }^{612}$ colorectal, ${ }^{510}$ stomach, ${ }^{79}$ and pancreatic ${ }^{79}$ cancer have been found in multiple cohort studies, but as yet no consistent pattern has emerged. The results of case-control studies that have reported results for tannery or leather workers have also been inconsistent. For example, many case-control studies of bladder cancer have examined the risk associated with occupations related to leather. Although some studies found increased odds ratios for bladder cancer associated with various occupations in the leather industry, ${ }^{14}$ others have not. ${ }^{1617}$ Several studies have also used biomonitoring to evaluate the mutagenicity and genotoxicity of exposures in the tanning industry. ${ }^{18-23}$ An increased frequency of chromosomal aberrations in peripheral blood lymphocytes has been found among leather tanners, ${ }^{18}{ }^{19}$ whereas negative results have been reported for urinary mutagenesis and the micronucleus test. ${ }^{20}$

The present paper updates a cohort study of workers employed in a tannery located in the city of Genoa, Italy published in $1984 .{ }^{10}$ The main findings of the earlier report were an excess of colorectal cancers (standardised mortality ratio (SMR) 186), a small excess of lung cancers (SMR 136), and two tumours of the tonsils (SMR 3080). For the present analysis, the entrance criteria for the cohort were expanded and the follow up period was extended by 15 years. The increased number of person-years and the longer period of follow up will allow a better evaluation of the relative risks for the less frequent causes of death and those with a long latency period.

\section{Subjects and methods}

The cohort consisted of workers employed at a factory which began leather tanning operations in the past century and stopped in 1988. The predominant activity was chromium tanning and retanning of leather for shoe uppers and purses with synthetic tannins. Finishing operations, including leather dying, were also performed at this factory.

The earlier report of this cohort was for 1044 workers who had been employed for six months or more, at least one day of which was between 1960 and 1979 with a corresponding follow up period from 1 January 1960 to 31 December 1979. There were 17632 personyears of follow up and a total of 117 deaths. For the update, both the period for entry into the cohort and the follow up period were expanded. The present study population consists of all workers employed for six months or more between 1 January 1955 and 12 May 1988, when the tannery was permanently closed. The follow up period for mortality is to 1 June 1994. The cohort for the present analysis is composed of 1244 subjects ( 870 men and 374 
Table 1 Deaths from all causes and person-years among tannery workers by sex and age

\begin{tabular}{llrlrrr}
\hline & \multicolumn{1}{l}{ Age } & & & \\
\cline { 2 - 6 } & $15-34$ & \multicolumn{1}{c}{$35-54$} & $55-64$ & $65-74$ & $\geqslant 75$ & \multicolumn{1}{c}{ Total } \\
\hline Men & $6 / 4234$ & $53 / 12261$ & $83 / 4834$ & $81 / 2251$ & $61 / 693$ & $284 / 24273$ \\
Women & $2 / 2390$ & $15 / 6108$ & $15 / 2310$ & $29 / 1021$ & $24 / 312$ & $85 / 12141$ \\
Total & $8 / 6624$ & $68 / 18369$ & $98 / 7144$ & $110 / 3272$ & $85 / 1005$ & $369 / 36414$ \\
\hline
\end{tabular}

women) with a total of 36414 person-years of follow up. Follow up has been successfully completed for 1190 people (95.7\%), 369 of whom ( $31 \%$ ) were identified as dead ( 284 men and 85 women). The cause of death was not known for seven subjects, and 54 others, corresponding to $4.3 \%$ of the cohort, were lost to follow up by 1 June 1994.

Name, date and place of birth, address at hire (sometimes omitted), date of hire, and date of retirement for all workers employed in the tannery were obtained from company records. Information on the department, supplied by a clerk of the tannery, was available only for 314 workers (25.2\%). Workers' vital status was ascertained through postal follow up. For each worker identified as dead, the death certificate was obtained from the municipality of residence, or from the local health districts, or for subjects who died in the Region of Liguria, from the Regional Mortality Registry. Causes of death were then coded according to the ninth revision of the international classification of diseases (ICD-9). Seven workers for whom no information on the cause of death could be obtained were considered dead at the date certified and included only in the calculation of all causes mortality.

The person-years at risk were stratified by sex, five-year age, and five-year calendar period and the number of expected deaths was then computed by applying the corresponding sex-age-calendar and cause specific Italian national mortality rates to the person-years at

Table 2 Mortality among male and female tannery workers in Genoa: 1955-94

\begin{tabular}{|c|c|c|c|c|}
\hline Cause of death (ICD-9) & Obs & $\operatorname{Exp}$ & $S M R$ & $(95 \% C I)$ \\
\hline All causes (000-999) & 369 & 372.29 & 99 & (90 to 110 ) \\
\hline All malignant cancers $(140-208)$ & 123 & 109.81 & 112 & (94 to 134 ) \\
\hline Oral cavity, pharynx (140-149) & 4 & 3.22 & 124 & (34 to 318 ) \\
\hline Oesophagus (150) & 2 & 2.36 & 85 & (10 to 306$)$ \\
\hline Stomach (151) & 10 & 12.64 & 79 & (38 to 146$)$ \\
\hline Colorectal cancers $(152-154)$ & 17 & 9.44 & 180 & (105 to 288 ) \\
\hline Small intestine, colon (152-153) & 10 & 6.03 & 166 & (80 to 305$)$ \\
\hline Rectum (154) & 7 & 3.41 & 206 & (83 to 423 ) \\
\hline Liver, biliary passages $(155-156)$ & 5 & 7.12 & 70 & (23 to 164$)$ \\
\hline Pancreas (157) & 3 & 3.96 & 76 & (16 to 221 ) \\
\hline Larynx (161) & 5 & 3.25 & 154 & (50 to 359$)$ \\
\hline Lung (162) & 29 & 28.17 & 103 & (69 to 148 ) \\
\hline Bone (170) & 2 & 0.91 & 220 & (27 to 795$)$ \\
\hline Connective tissue (171) & 0 & 0.17 & 0 & ( 0 to 1740$)$ \\
\hline Melanoma (172) & 0 & 0.71 & 0 & (0 to 423$)$ \\
\hline Breast (174) & 6 & 4.79 & 125 & (46 to 273 ) \\
\hline Prostate (185) & 3 & 4.47 & 67 & $(14$ to 196$)$ \\
\hline Bladder (188) & 10 & 4.13 & 242 & (116 to 446$)$ \\
\hline Kidney (189) & 1 & 2.00 & 50 & (1 to 278 ) \\
\hline Brain (191) & 4 & 2.38 & 168 & (46 to 431$)$ \\
\hline Lymphoma (200-202) & 1 & 2.83 & 35 & (1 to 197 ) \\
\hline Leukaemia (204-208) & 0 & 3.42 & 0 & (0 to 88$)$ \\
\hline Diabetes $(250)$ & 12 & 9.23 & 130 & (67 to 227 ) \\
\hline Diseases of nervous system (320-389) & 6 & 5.30 & 113 & (42 to 246$)$ \\
\hline Diseases of circulatory system (390-459) & 113 & 148.11 & 76 & (63 to 92$)$ \\
\hline Diseases of respiratory system $(460-519)$ & 24 & 25.18 & 95 & (61 to 142$)$ \\
\hline Diseases of digestive system (520-579) & 30 & 28.88 & 104 & (70 to 148$)$ \\
\hline Cirrhosis (571) & 16 & 18.5 & 86 & (49 to 140$)$ \\
\hline Diseases of genitourinary system (580-629) & 3 & 5.75 & 52 & (11 to 153$)$ \\
\hline Ill defined conditions $(780-799)$ & 10 & 5.85 & 171 & (82 to 315$)$ \\
\hline Accidents (800-999) & 25 & 22.29 & 112 & (73 to 166$)$ \\
\hline
\end{tabular}

risk. To take into account differences between national rates and the local mortality patterns, expected deaths were also calculated from the mortality rates for Liguria. This analysis was restricted to the period 1970-94, as data from 1955 were not available. The SMRs were obtained by computing the ratio of the observed to the expected deaths for each specific cause of death. Two sided $95 \%$ confidence intervals (95\% CIs) for each SMR were calculated based on a Poisson distribution for the observed deaths. ${ }^{24}$ Stratified analyses were performed for duration of employment, years since first employment, and calendar year of first employment, and $\chi^{2}$ statistics were computed for test of the trend. ${ }^{24}$ Lagging of exposure by 10,20 , and 30 year intervals was used to allow for a latency period. ${ }^{25}$ Personyears and SMRs (95\% CIs) were calculated with the Epilog statistical software. ${ }^{26}$

\section{Results}

Table 1 shows the distribution of the personyears and deaths by sex and age. The mean age of the cohort at hire was 30.4 , with a mean period of 32.0 years of follow up. Table 2 shows the observed and expected numbers of deaths and the SMRs for the main cancer sites and other main causes of death. Mortality due to all causes was similar to that which would be expected based on national mortality rates. Decreased SMRs were found for diseases of the circulatory system (SMR 76), non-malignant respiratory diseases (SMR 95), cirrhosis (SMR 86), and genitourinary diseases (SMR 52), and for a number of cancer sites, such as leukaemia ( 0 observed, 3.42 expected).

Mortality for all cancers was $12 \%$ higher than expected. The most remarkable excess observed in this cohort was for bladder cancer (SMR 242; 95\% CI 116 to 446). Consistent with results of earlier analyses of this same cohort, an increased SMR was observed for colorectal cancer (SMR 180), based on excesses of both colon (SMR 166) and rectal cancer (SMR 206). Increased SMRs were also observed for some of the less common cancer sites, such as the larynx (SMR 154), bone (SMR 220), and brain (SMR 168), although these excesses were based on only a few cases. Differences among sexes were generally small for the more common causes of death, with the exception of pancreatic cancer, for which an excess was found among women (three observed $v 0.84$ expected; SMR 355) and a deficit among men (zero observed $v 3.12$ expected).

Analyses were repeated with regional mortality rates (1970-94). Given that the results were essentially the same as the analyses with Italian mortality rates for the same years, only the analyses based on national mortality rates (1955-94) are presented.

Table 3 shows the results of the analyses of leather tanners by duration of exposure, time from first employment, and year of hire for bladder, colorectal, and lung cancer. The relative risk of colorectal cancer seemed to be highest among workers employed for five or more years. Although most tannery workers 
Table 3 Relative risk of death by duration of exposure, time from first employment, and calendar year of first employment for tannery workers in Genoa

\begin{tabular}{|c|c|c|c|c|c|c|c|c|c|c|c|c|}
\hline & \multicolumn{4}{|c|}{ Bladder cancer } & \multicolumn{4}{|c|}{ Colorectal cancer } & \multicolumn{4}{|c|}{ Lung cancer } \\
\hline & Obs & $\operatorname{Exp}$ & $S M R$ & $(95 \% C I)$ & Obs & $\operatorname{Exp}$ & $S M R$ & $(95 \% C I)$ & Obs & $\operatorname{Exp}$ & $S M R$ & $(95 \% C I)$ \\
\hline \multicolumn{13}{|c|}{ Duration of exposure (y): } \\
\hline$<5$ & 3 & 0.69 & 437 & (90 to 1277 ) & 2 & 1.67 & 120 & (14 to 432 ) & 9 & 5.99 & 150 & (69 to 285 ) \\
\hline $5-14$ & 0 & 1.08 & 0 & (0 to 278 ) & 5 & 2.51 & 199 & (65 to 465 ) & 7 & 7.51 & 93 & (37 to 192 ) \\
\hline$\geqslant 15$ & 7 & 2.36 & 296 & (119 to 610$)$ & 10 & 5.25 & 190 & (91 to 350 ) & 13 & 14.67 & 89 & (47 to 152 ) \\
\hline \multicolumn{13}{|c|}{ Time from first employment } \\
\hline & & & & & & & & & & & & \\
\hline $\begin{array}{l}<20 \\
20-29\end{array}$ & 2 & 0.71 & 282 & (34 to 1019) & 1 & 2.04 & 49 & (2 to 274) & 6 & 6.22 & 97 & (35 to 210 ) \\
\hline $20-29$ & 2 & 1.22 & 163 & $(20$ to 590$)$ & 10 & 2.84 & 352 & (169 to 647$)$ & 8 & 9.52 & 84 & (36 to 166 ) \\
\hline$\geqslant 30$ & 6 & 2.19 & 274 & (100 to 595$)$ & 6 & 4.56 & 132 & (48 to 287 ) & 15 & 12.43 & 120 & (68 to 199$)$ \\
\hline \multicolumn{13}{|c|}{$\begin{array}{l}\text { Calendar year of first } \\
\text { employment: }\end{array}$} \\
\hline Before 1941 & 2 & 0.75 & 267 & (32 to 964 ) & 4 & 1.62 & 247 & (67 to 632 ) & 3 & 3.36 & 89 & (18 to 261 ) \\
\hline $1941-50$ & 3 & 0.91 & 331 & (68 to 967 ) & 6 & 2.23 & 269 & (99 to 586 ) & 7 & 5.22 & 134 & (54 to 276 ) \\
\hline $1951-60$ & 3 & 1.55 & 194 & (40 to 567$)$ & 3 & 3.63 & 83 & (17 to 242 ) & 11 & 12.21 & 90 & (45 to 161$)$ \\
\hline $1961-88$ & 2 & 0.93 & 216 & (26 to 779 ) & 4 & 1.97 & 203 & (55 to 520 ) & 8 & 7.40 & 108 & (47 to 213 ) \\
\hline Total & 10 & 4.13 & 242 & (116 to 446 ) & 17 & 9.44 & 180 & (105 to 288 ) & 29 & 28.17 & 103 & (69 to 148 ) \\
\hline
\end{tabular}

who had died of bladder cancer had been employed for 15 or more years (SMR 296), no clearcut trend of SMRs by duration of exposure was found. No recognisable patterns emerged from the analyses by years since first employment or calendar period of hire, although the highest risks for both bladder cancer (SMR 301, 95\% CI 97 to 701) and colorectal cancer (SMR 260, 95\% CI 124 to 478) were found among workers first employed before 1951. Cross tabulation of the results by categories of duration and years since first employment, obviously based on a few cases, failed to produce any suggestive pattern. Lagging of exposures by 10, 20, and 30 years also did not increase the information from the analysis.

\section{Discussion}

The most striking observation in this study was the considerable excess of bladder cancer (SMR 242, 10 observed $v 4.13$ expected), plausibly linked to work in the tannery. Bladder cancer has been associated with dyes used in tanning, in particular benzidine azo dyes and anilines which were widely used in this tannery. ${ }^{11}$ No excess of bladder cancer was found in the previous analysis of mortality among this cohort, possibly due to the shorter follow up period. Chen and colleagues ${ }^{12}$ found an excess of bladder cancer (standardised incidence ratio 273) among tannery workers in Shanghai who had been exposed to benzidine derived dyes and a smaller excess was found among Tuscan tannery workers. ${ }^{6}$ Although the results of cases-control studies are mixed, their findings are hard to interpret because tannery workers are often grouped with other leather industry workers, such as shoemakers. Shoe workers are likely to have higher exposure to leather dust and solvents used in glues, including benzene, than most tannery workers. On the other hand, tannery workers will generally have much higher exposure to tanning and dyeing agents. Even the grouping of tannery workers into a single group may hide significant differences in exposure. The two main tanning processes (chrome and vegetable) differ not only in tanning agents used; chrome tanneries make much greater use of dyes, pigments, and solvents. Although confounding due to smoking habit cannot be completely ruled out, its occurrence in these workers is unlikely given the low SMR found for lung cancer.

In this study an excess of colorectal cancer was found, which was also found in the 1984 analysis. An excess of colorectal cancer has occurred in fur dressers and dyers ${ }^{513}$ and among shoe workers, ${ }^{27}$ but has not been found in other studies of tannery workers. It is unclear which, if any, exposures among tannery workers could be responsible for this finding. The risks for both colorectal and bladder cancer both seemed to be higher among workers first hired before the $1950 \mathrm{~s}$, although the risk was also increased in later periods. This could be due to changes over time in the process or chemicals used or, for bladder cancer, may reflect a long latency period.

A small excess of lung cancer was described in our first paper ( 14 observed $v 10.3$ expected; SMR 136), but was not confirmed in this cumulative update of the cohort. An excess risk of lung cancer among chrome tannery workers is plausible, given their potential exposure to hexavalent chromium, a well known respiratory carcinogen, and there is some evidence from other epidemiological studies. One study of chrome tannery workers found a large excess of lung cancer ${ }^{28}$ whereas small excesses have been found in other studies. ${ }^{67}$ However, it is likely that exposure to hexavalent chromium has decreased over time, due to the switch from the double to the single bath chrome tanning process. The possible presence of an excess of lung cancer in this cohort among workers employed in earlier periods was hard to evaluate due to the few person-years and the lack of information on process changes that occurred during the 1940 s and 1950 s.

One of the most intriguing results of our first study was the presence of two deaths for tumour of the tonsils ( 0.07 deaths expected). No additional cases were found in the new follow up, even though the person-years had more than doubled. Given the small numbers, it was likely that this was a chance occurrence, 
although we cannot rule out the possibility that these cases were associated with exposures that were only present during early periods.

The extended follow up period of this study and the larger number of deaths observed resulted in an increase in study power and allowed the examination of the results stratified by surrogate indicators of exposure. Another objective of this update was to acquire more detailed information on exposures among this population. There are many, potentially carcinogenic substances present in various steps of the tanning process, and exposures may vary greatly between different departments. Unfortunately, departmental information on individual people was only available for a few workers and the closure of the factory prevented the collection of additional data. The inherent limiting factors of this study (the use of surrogate indicators of exposure and the low statistical power) did not enable us to draw any firm conclusion about the presence of doseresponse relations.

In conclusion, this study found our cohort of tannery workers to have an excess risk of bladder and colorectal cancer. The increased bladder cancer mortality is likely to be due to exposure to leather dyes based on benzidine, whereas potential causes for an excess of colorectal cancer are not known.

We are grateful to Rag $M$ Conzi and Miss $C$ Schezzi for their kind collaboration in collecting the company records, to $\mathrm{Dr} C$ Lando for coding causes of death and to Dr P Assereto and Dr $P$ Padovani for their help in data collection and data input. We thank also the Regional Mortality Registry of the Regione Liguria for providing causes of death in Liguria from 1989-93.

1 International Agency for Research on Cancer. LARC monographs on the evaluation of the carcinogenic risk of chemicals to humans: wood, leather and some associated industries. Vol 25. Lyon: IARC, 1981.

2 Hills B, Fajen J. In: C Zenz, ed. Leather manufacturing in occupational medicine: principles and practical applications. 2nd ed. Chicago: Year Book Medical Publishers, 1988:1036-9.

3 International Agency for Research on Cancer. IARC monographs on the evaluation of the carcinogenic risk of chemicals to graphs on the evaluation of the carcinogenic risk of chemicals to
humans: overall evaluations of carcinogenicity: an updating of humans: overall evaluations of carcinogenicity: an updating of

IARC monographs. Vol 1-42. Suppl 7. Lyon: IARC, 1987.

Stern FB, Beaumont JJ, Halperin WE, Murthy LI, Hills BW,
Fajen JM. Mortality of chrome leather tannery workers and chemical exposures in tanneries. Scand $\mathcal{f}$ Work Environ Health 1987;13:108-17.

5 Guay D, Siemiatycki J. Historic cohort study in Montreal's fur industry. Am 7 Ind Med 1987;12:181-93.

6 Seniori Costantini A, Paci E, Miligi L, Buiatti E, Martelli C, Lenzi S. Cancer mortality among workers in the Tuscan tanning industry. $\mathrm{Br} \mathcal{F}$ Ind Med 1989;46:384-8.
7 Mikoczy Z, Schutz A, Hagmar L. Cancer incidence and mortality among Swedish leather tanners. Occup Environ Med 1994;51:530-5.

8 Pippard EC, Acheson ED, Winter PD. Mortality of tanners. Br f Ind Med 1985;42:285-7.

9 Edling C, Kling H, Flodin U, Axelson O. Cancer mortality among leather tanners. $B r \mathcal{F}$ Ind Med 1986;43:494-6.

10 Puntoni R, Valerio A, Cresta E, Filiberti R, Bonassi S, Vercelli $M$. Studio di mortalità fra $i$ lavoratori di una conceria. Med Lav 1984;75:471-7.

11 Valerio A. Indagine prospettica sulla mortalita' per tumore fra $i$ lavoratori di una conceria di Genova (1960-9) [ $\mathrm{PhD}$ Thesis]. Genoa: University of Genoa, 1984

12 Chen JG. A cohort study on the cancer experience among workers exposed to benzidine-derived dyes in Shanghai leather-tanning industry. Chinese fournal of Preventive Medicine 1990;24:328-31.

13 Sweeney MH, Walrath J, Waxweiler RJ. Mortality among retired fur workers: dyers, dressers (tanners) and service workers. Scand f Work Environ Health 1985;11:257-64.

14 Kunze E, Chang-Claude J, Frentzel-Beyme R. Life style and occupational risk factors for bladder cancer in Germany. A case-control study. Cancer 1992;69:1776-90.

15 Vineis P, Magnani C. Occupation and bladder cancer in males: a case-control study. Int $\mathcal{F}$ Cancer 1985;35:599-606.

16 La Vecchia C, Negri E, D’Avanzo B, Franceschi S. Occupation and the risk of bladder cancer. Int $\mathcal{F}$ Epidemiol 1990;19: 264-8.

17 Siemiatycki J, Dewar R, Nadon L, Gerin M. Occupational risk factors for bladder cancer: results from a case-control study in Montreal, Quebec, Canada. Am $\mathcal{F}$ Epidemiol 1994; study in Montrea

18 Hamamy HA, Al Hakkak ZS, Hussain AF. Chromosome aberrations in workers at a tannery in Iraq. Mutat Res 1987;189:395-8.

19 Sbrana I, Caretto S, Battaglia A. Chromosomal aberration analysis of workers in tannery industries. Mutat Res 1991;260:331-6.

20 Gonzalez Cid M, Loria D, Nagel R, Matos E. Genotoxic monitoring of workers of a chemical industry: sister chromatid exchange and Salmonella-S9 test. $\mathcal{F}$ Exp Clin Cancer Res 1983;4:415-9.

21 Gonzalez Cid M, Loria D, Vilensky M, Miotti JL, Matos E. Leather tanning workers: chromosomal aberrations in peripheral lymphocytes and micronuclei in exfoliated cells in urine. Mutat Res 1991;259:197-201.

22 Migliore L, Parrini M, Sbrana I, Biagini C, Battaglia A, Loprieno N. Micronucleated lymphocytes in people occuLoprieno N. Micronucleated lymphocytes in people occupationally exposed to potential environment
contaminants: the age effect. Mutat Res 1991;256:13-20.

23 Seniori Costantini AS, Paci E, Scala D, Cariaggi P, Cipparrone G, Confortini M, et al. Monitoring the carcinogenic risk in tannery workers by means of desquamative lung and bladder cytology and urinary mutagenicity. Ann Occup Hyg 1987;31:21-30.

24 Breslow NE Day NE Statistical methods in cancer research. Vol 2. The design and analysis of cohort studies. Lyon: International Agency for Research on Cancer, 1987. (IARC sci publ 82.)

25 Checkoway H, Pearce N, Hickey JL, Dement JM. Latency analysis in occupational epidemiology. Arch Environ Health 1990;45:95-100.

26 Epicenter Software. Epilog plus: statistical package for epidemiology and clinical trials. Pasadena, CA: Epicenter Software, 1989.

27 Pippard EC, Acheson ED. The mortality of boot and shoe makers, with special reference to cancer. Scand $¥$ Work makers, with special reference
Environ Health 1985;11:249-55.

28 Bonassi S, Merlo F, Puntoni R. Epidemia di tumori polmonari in una conceria del biellese (VC). Epidemics of lung tumors in a Biella tannery. Epidemiologia e prevenzione $1990 ; 44: 25-30$. 